\title{
Categories of insight and their correlates: An exploration of relationships among classic-type insight problems, rebus puzzles, remote associates and esoteric analogies
}

\section{ABSTRACT}

A central question in creativity concerns how insightful ideas emerge. Anecdotal examples of insightful scientific and technical discoveries include Goodyear's discovery of the vulcanization of rubber, and Mendeleev's realization that there may be gaps as he tried to arrange the elements into the Periodic Table. Although most people would regard these discoveries as insightful, cognitive psychologists have had difficulty in agreeing on whether such ideas resulted from insights or from conventional problem solving processes. One area of wide agreement among psychologists is that insight involves a process of restructuring. If this view is correct, then understanding insight and its role in problem solving will depend on a better understanding of restructuring and the characteristics that describe it.

This article proposes and tests a preliminary classification of insight problems based on several restructuring characteristics: the need to redefine spatial assumptions, the need to change defined forms, the degree of misdirection involved, the difficulty in visualizing a possible solution, the number of restructuring sequences in the problem, and the requirement for figure-ground type reversals. A second purpose of the study was to compare performance on classic spatial insight problems with two types of verbal tests that may be related to insight, the Remote Associates Test (RAT), and rebus puzzles. In doing so, we report on the results of a survey of 172 business students at the University of Waikato in New Zealand who completed classic-type insight, RAT and rebus problems.

Keywords: Insight problem solving, creative problem solving, spatial insight problems, remote associates, rebus puzzles

\section{INTRODUCTION}

Many scientific discoveries appear to involve a type of creative problem solving that involves transformational shifts in approaching the problem. Examples include Goodyear's discovery of the vulcanization of rubber, Banting and Best's development of insulin to treat diabetes, and Mendeleev's realization that there may be gaps as he tried to arrange the elements into the Periodic Table (Akin, Akin E Heinz III, 1996; Kedrov, 1966-1967). A distinctive characteristic of these 
discoveries is the experience of a "breakthrough", where the problem solver is able to move from not knowing how to solve a problem to a feeling of knowing how to proceed (Mayer, 1996). The concept of insight was introduced by Gestalt psychologists over 75 years as a way of describing this apparently unique problem solving process. Insight is described as "restructuring" - a radical, and often sudden, change in how a problem is conceived (Weisberg, 1996).

Insight involves modifying or rejecting previously accepted assumptions (Newell $\mathcal{E}$ Simon, 1972) and accepting more appropriate ones (Sternberg \& Davidson, 1983; Schooler E Melcher, 1995; Smith, Ward E Finke, 1995; Tardif E Sternberg, 1988). It is ". . . seeing a problem in a new light, often without awareness of how the new light was switched on" (Jung-Beeman, Bowden, Haberman, Frymiare, Arambel-Liu, Greenblatt, Paul, Reber, \& Kounios, 2004: 507). Weisberg (1996) suggests that insight occurs when a problem is solved through restructuring. For this to occur, a problem solver "must carry out multiple solutions attempts, and the correct solution must be the result of a problem representation different from that which was the basis of the initial solution(s)" (Weisberg, 1996: 164). JungBeeman et al., (2004) suggested four features which might describe insight. Problem solvers become stuck or face an impasse; solvers cannot usually report the processing leading to the solution; solvers find that the solution arises suddenly: and performance on insight problems is connected to cognitive and creative processes which are very different than for non-insight problems.

However, to others, insight problem solving entails the same processes as normal problem solving, and involves no emergent properties. In experiments using the 9-dot, 4-dot, and triangles problem, Weisberg and Alba (1981) concluded that insight and fixation do not help explain the problem solving process. They emphasized that the solution to insight problems, in two of the problems they studied, can be explained in other ways. That is, "people apply their knowledge to new problems, and if their knowledge is not directly useful, they try to produce something new that will solve the problem through a straightforward extension of what they know. No exotic processes, such as a sudden insight, are involved" (Weisberg \& Alba, 1981: 189). The two sides to this debate are described as the "special-process" and the "business-as-usual' views.

If insight involves restructuring processes, the heart of understanding insight and its role in problem solving seems to rely on a better understanding of restructuring and the characteristics that describe it. It has been suggested that there may be different forms of restructuring (Ohlsson, 1992; Weisberg, 1996). In addition, some problems which are thought to require insight might not be solved through a classical definition of insight (Weisberg, 1996). The main purpose of this article is to develop a better understanding of types of restructuring which might distinguish between different insight problems. A secondary purpose is to examine performance on two other types of problem (Remote Associates and rebus puzzles) whose solutions potentially may involve restructuring. In pursuing these purposes, we report on the results of a survey of 172 business students at the University of Waikato in New Zealand who completed insight tests and classic-type insight problems.

Our review of the recent literature reveals the importance of restructuring in understanding insight and the character of different types of insight problems. The following paragraphs review different views of restructuring and how six restructuring characteristics might be used to classify different insight problems. 
Tupes of restructuring

Weisberg (1996) conducted a conceptual analysis of a sample of candidate insight problems, and concluded that the associated restructurings were striking in their heterogeneity, a factor that he considered a challenge for a single-process theory of restructuring. Previously, Ohlsson (1992) had proposed three different types of restructuring; elaboration, re-encoding and constraint relaxation. Elaboration refers to a representational change brought about by the addition of information, which can be productive if the original representation is incomplete. Re-encoding is described as "...rejecting one or more layers of interpretation" and reaching a new interpretation of the problem. Both elaboration and re-encoding are considered to involve the initial problem state. In contrast, the third mechanism, constraint relaxation, is defined in terms of changing an initially constrained or inappropriate representation of the goal state.

Ansburg and Dominowski (2000) used Ohlsson's taxonomy to categorize verbal insight problems. They reported difficulty in finding multiple examples involving re-encoding, and classified 60 problems as involving either elaboration or constraint relaxation (or "other"), to a level of 100\% agreement between two judges. The purpose was to help develop training procedures aimed at the different restructuring processes. What they found, however, was that training on problems, supposed to involve only elaboration, facilitated subsequent performance on both elaboration and constraint relaxation problems to an equal degree. They conjectured that the training directed specifically at the mechanism of elaboration had in fact a more general effect at a higher procedural level.

An alternative explanation of the Ansburg and Dominowski (2000) finding is that there is, in fact, no real distinction between the proposed types of restructuring. While Ansburg and Dominowski's two raters achieved 100\% agreement in their classifications, the distinction between some problems appears potentially subjective and equivocal, and there are instances of discrepancies in the literature. For example, while Ansburg and Dominowski (2000) classified the prisoner and rope problem (Metcalfe $\mathcal{E}$ Wiebe, 1987) as requiring elaboration, Isaak and Just (1996) described it as an example of constraint relaxation. Also, Isaak and Just considered the pendulum solution to Maier's (1931) two strings problem to involve constraint relaxation, while Ohlsson (1992) presented it as an example of re-encoding.

One reason why such inconsistencies arise is because different authors conceptualize the associated solution processes in different ways. Weisberg (1996), for example, has noted that Ohlsson's (1984) analysis of the steps involved in solving the "Two strings" problem differed from Maier's (1931) analysis. The coin triangle problem (Metcalfe, 1986a) is another example where different interpretations of the required restructuring have been offered. The problem is to reverse a triangular arrangement of 10 coins by moving three coins only. (See Figure 1.)

FIGURE 1.
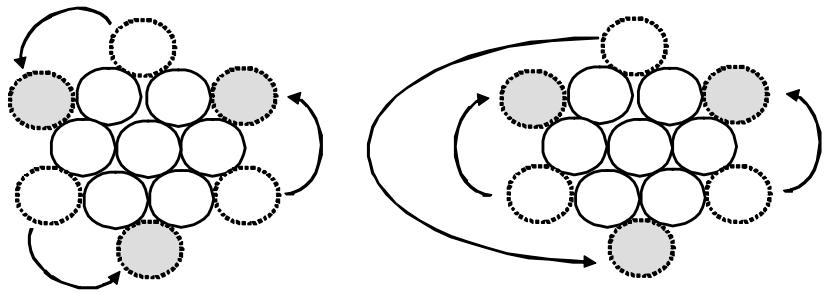
The restructuring required to solve the coin triangle problem has been interpreted in several different ways. Weisberg (1996) describes the restructuring in terms of an initial perception of an undifferentiated collection of coins to one of a central rosette flanked by three moveable coins. Metcalfe (1986b) provides a similar interpretation. In contrast, Isaak and Just (1996) describe the insight solution in terms of translational moves across the median axis, rather than rotational moves, as illustrated in Figure 1. Chronicle, MacGregor $\mathcal{E}$ Ormerod (2004) found that, of 36 correct solutions, 8 were compatible with the representation on the left and 19 with the one on the right. They also provided evidence that the latter solution was consistent with a hill-climbing strategy that did not require restructuring. The example demonstrates that, even with a "standard" insight problem, issues exist as to the nature of the restructuring presumed to underlie the insight or, in this case, whether the solution involves insight at all.

While Ohlsson's (1992) theory represents an important contribution that provided a stimulus to the field, the psychological reality of the proposed types of restructuring remains unproven, as Ohlsson himself recognized (Ohlsson, 1992). As noted above, one of the difficulties in identifying types of restructuring may be that different researchers adopt different, possibly incorrect, assumptions about the restructuring required to solve a given problem. In addition, there is no generally-accepted definition of an "insight problem" (Chronicle, MacGregor \& Ormerod, 2004; Weisberg, 1996). Indeed, the term "insight problem" should be regarded as a relative term, where a problem that involves insight for one person may not for another.

\section{Selection of insight problems}

To explore the possibility of different forms of restructuring, we first selected a set of problems to examine. This selection was guided by several criteria. First, we restricted the choice to problems that involved a strong spatial component. We did so because the originators of the concept of restructuring typically used examples of this type (Wertheimer, 1945), as did classic empirical studies of the phenomenon (Duncker, 1945; Maier, 1931). Second, we selected problems that covered a relatively wide range of difficulty (limited by the constraint that problems involving insight are typically difficult to solve). Third, we chose problems that had been associated with insight solutions in previous research, or that were analogs of such problems. The problems and their source(s) are shown in Table 1.

For the ten problems, there were four types of evidence that solutions involve insight. The first was evidence that the solution appeared suddenly or unexpectedly, using "feeling of warmth" ratings (Metcalfe \& Wiebe, 1987) or other means. This was the case for problems 1 (Chronicle et al, 2004), 2, 8, $9 \& 10$ (Metcalfe $\varepsilon$ Wiebe, 1987) in Table 1 . The second was evidence that solution rates were increased through training designed to facilitate insight. This applied to problems 1, 5 and 7 (Cunningham \& MacGregor, 2008) and problems 3, 4, 5, and 6 (Walinga, 2007). The third was evidence of differential effects of verbal overshadowing on solving insight and non-insight problems (Schooler, Ohlsson E Brooks, 1993). This supported our selection of problems 2 and 4 . The fourth was evidence based on a clustering analysis of 34 problems, 24 of which were thought to involve insight (Gilhooly $\&$ Murphy, 2005). The results supported our selection of problems 2 and 4, but also suggested that problem 10 may be solved without insight. 


\section{CHARACTERISTICS DEFINING CLASSIC-TYPE INSIGHT PROBLEMS}

Our understanding of previous studies and our experimental research on puzzlelike and realistic problems (Cunningham and MacGregor, 2008) helped us define five characteristics which might be involved in insight problems. In addition, in order to encourage an open-ended, inductive approach to identifying characteristics, we used a structured procedure called the RepGrid (Repertory Grid) or Role Construct Repertory Test (Kelly, 1955). The RepGrid technique was devised by Kelly to assist in counselling his clients, although it has been applied in other settings (Bannister \& Mair, 1968; Walker E Winter, 2007). In our application, two of the authors independently carried out a series of comparisons based on different subsets of the 10 insight problems shown in Table 1).

The comparison procedure consisted of randomly selecting three problems and identifying an insight characteristic shared by two of the problems and not by the third. Implicit in our minds was that the characteristic should be related to the restructuring necessary to solve the problem. Each author independently carried out the procedure five times, which helped us in clarifying and focusing our characteristics and in identifying two new characteristics (\#2 and \#6 below) and in discarding another.

We propose that insight problems can be described by restructuring characteristics such as: the need to redefine spatial assumptions; the need to change defined structures or forms; the degree of misdirection involved; the difficulty in visualizing a possible solution; the number of restructuring sequences in the problem; and the requirement for figure-ground type reversals.

1. The need to redefine spatial assumptions. Some insight problems require a shift in one or more spatial assumptions involving the arrangement of objects, connection of words or phrases, or the visual placement of materials. Such problems illustrate the movement of an object in a one dimensional space, changing the perspective (from back to front, or from side to side) from which to view the problem, or altering the type of assumptions (spatial, visual, relationship, or language use). Examples might include the six coin problem (described below) or carpentry operations which might involve altering the direction of a heating pipe. MacGregor and Cunningham (2008) classified 100 rebus problems and identified 16 different principles or assumptions that problem solvers might have to reinterpret in solving a problem. The most frequently identified assumption in $61 \%$ of the 100 instances, required problems solvers to re-interpret spatial relations or positions of words. Individual rebuses ranged from having a minimum of one to a maximum of four of these different principles. The experimental results indicated that participants solved more problems that involved breaking one assumption than two or more, suggesting that problems with more assumptions were more difficult to solve.

2. The need to change defined structures or forms. Several insight problems require that the problem solver either dismantle, change, or restructure an existing form or figure before developing something new, as in the coin triangle or necklace problems. Others are unstructured and require only the construction or structuring based on an array of the evidence and smaller parts, such as the cross. This may be analogous to the transformational 
TABL $\in$ 1. Description of Problems Used in Survey.

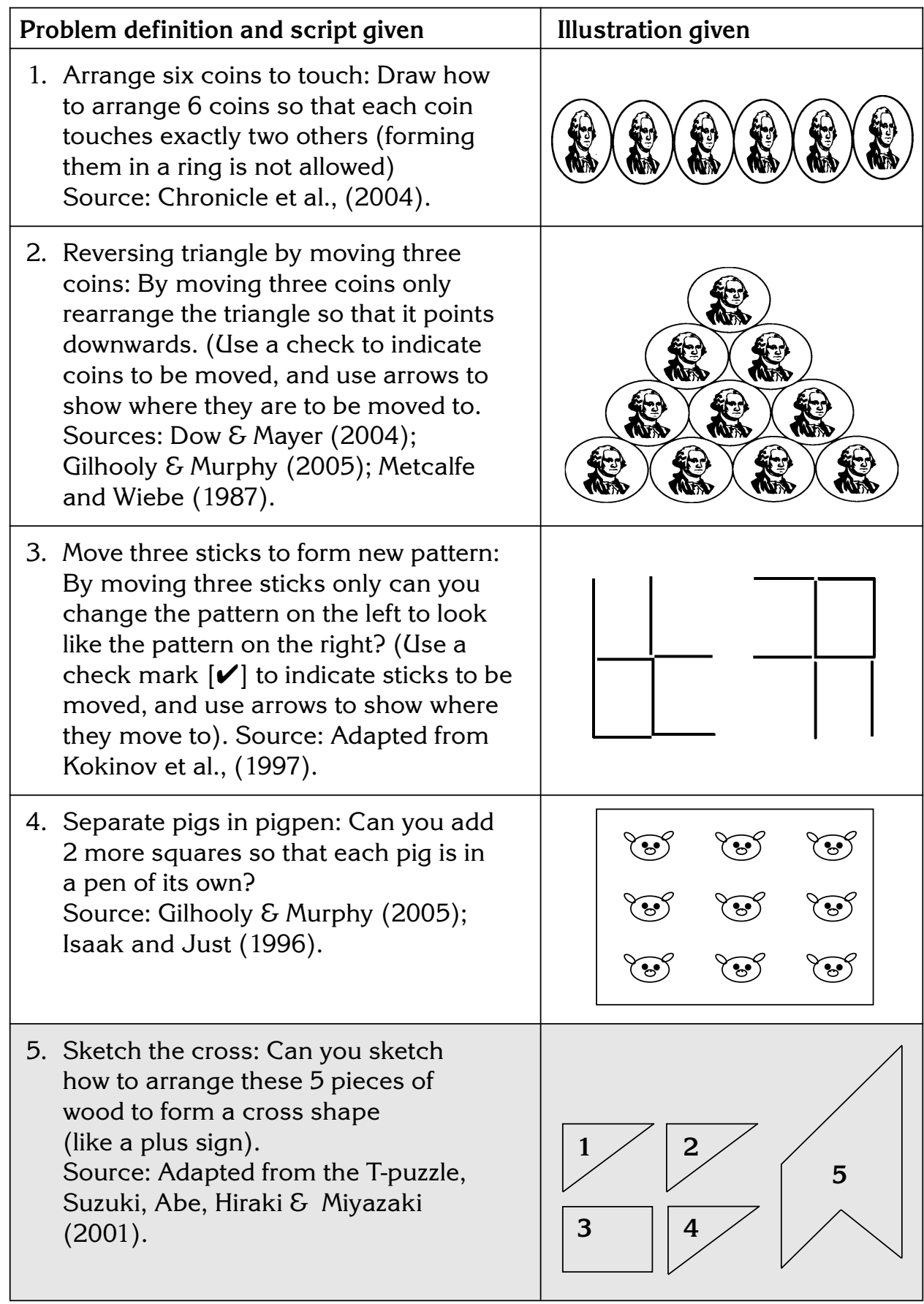




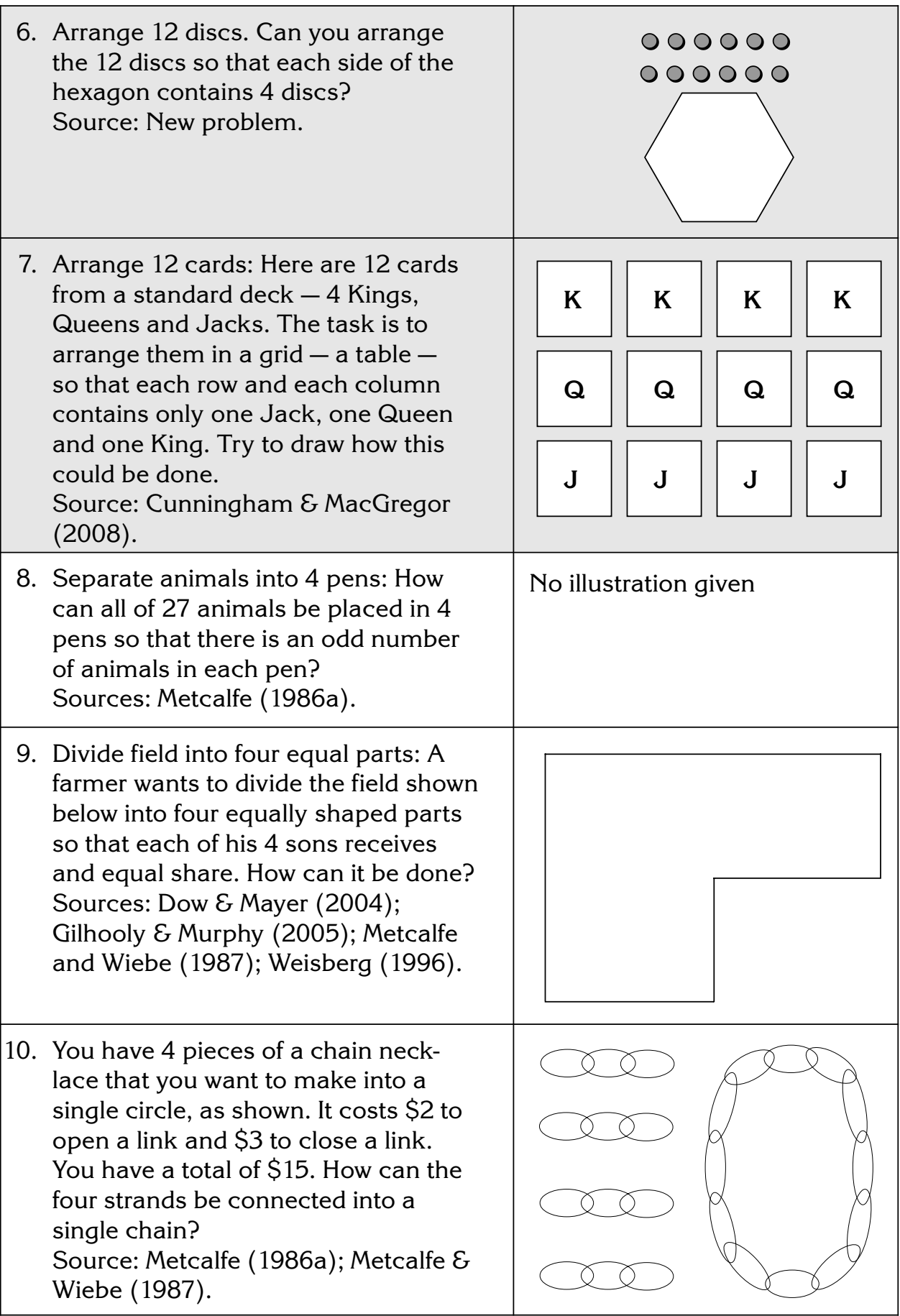


experiences required in redesigning an existing organization as opposed to designing a new one where there are no existing structures and procedures to dismantle. In the same sense, Wii's inventors redesigned the remote (controller) and devised a Wiimote to allow players to move about a room in playing a video game while IPod's inventors re-configured the physical dimensions of a hard drive so that it could be used for listening to music while walking and running.

3. The degree of misdirection involved. Some insight problems misdirect the problem solver away from a possible solution because the information defining them is misleading. Some insight problems (arranging 12 discs or placing all animals in 4 pens) might illustrate some misdirection, as the solution requires the twisting of the meaning of certain words beyond their conventional usage. Misdirection can also result because problem solvers assume that one approach is more acceptable than others or that a new and promising solution path might not be fruitful. For example, scientists were wedded to a view that there were no new planets in the Kuiper Belt area where Pluto exists. Even when a larger body was discovered, it was rejected as not being a planet (even though it had similar qualities as the then-planet Pluto had).

4. The difficulty in verifying what the solution would look like. For some insight problems, there are visible and recognized solutions states. For example, the goal state for reversing the triangle and moving three sticks is presented as the problem solver begins to solve the problem. In other puzzles, such as the nine-dot problem, the goal state is presented in a more abstract way and is not directly visible (MacGregor, Ormerod, and Chronicle, 2001). In the same way, some goal states of real-life insight problems may be visible and the problem is rather how to reach them. For example, how can the climber reach the summit? In other cases, the goal state is represented in some more abstract sense, such as: What is the structure of DNA?

5. The sequential character of the problem. Insight problem solving might not always involve one major "Aha" moment or major step, but may instead involve a sequence of steps (Weisberg, 1986; Perkins, 1981). MacGregor, Ormerod, and Chronicle (2001) suggested that the nine-dot problem might have many of the same qualities as hill climbing and involve a number of "look-ahead" strategies. The "aha" experience might illustrate the sequences after the insights have occurred (Chronicle et al, 2004) that occur in problem solving.

Similar sequences might have occurred for Mendeleev as he tried to develop a way to display the chemical elements in his textbook. As a first step, he was able to reduce the number of comparisons and see patterns when he compared the elements on their atomic properties and ordered them according to their atomic weights. Before the second breakthough occurred, he was under pressure to finish his work because he was leaving on a trip the next day. Because handwriting was cumbersome and because he was a player of the card game patience, he might have quickly grasped the idea of using cards to organize the elements (Akin, Akin \& Heinz III, 1996).

In organizing the elements, the cards allowed him to see an order of how the properties of the elements can be ordered in a periodic relationship to their weights. One dimension represented the atomic weight and the second 
was the general chemical properties. He also saw that there were gaps because of unknown elements. This was the insight that was needed because he was previously expecting that everything might fit in a $2 \times 2$ matrix. One of the greatest contributions of the table was in helping people recognize that other elements might exit, thus encouraging further discovery.

6. Figure-ground property. Some insight problems involve figure ground reversals that appear to be analogous to those involved in reversible figures. With such images, like the candlestick/two faces shown in Figure 2, focusing on one makes it impossible to see the second. When the candlestick interpretation is focal, the "two faces" interpretation becomes background and remains unseen, and vice versa. Reversible figures provide a striking perceptual demonstration of how we can restructure or see a situation in different ways at different times. A similar type of conceptual restructuring may result in an insight, by bringing into immediate perspective a solution which we were not previously able to see.

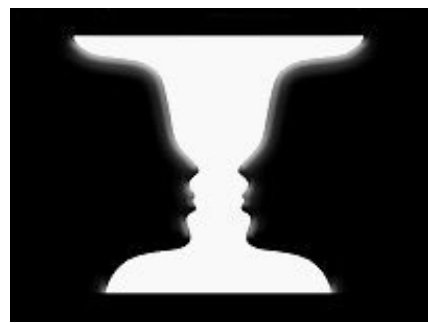

fIGURE 2. The Candlestick-Two Faces Reversing Figure.

\section{Application}

Our theory focuses on the characteristics of insight problems and the implication that some problems illustrate more characteristics of restructuring (Weisberg, 1996; Isaak E Just, 1996). Understanding a problem's characteristics might provide an understanding of why some problems are more difficult than others or how different problem solving strategies might be more useful than others. These characteristics might allow us to understand the differences between puzzle-like problems such as the nine-dot problem, and real ones, such as Mendeleev was trying to solve in developing a classification of chemical elements.

Hypothesis 1: Insight problems which share common restructuring characteristics may exhibit similar levels of difficulty. In previous experiment, we compared performance on rebus problems with a theoretical measure of difficulty (MacGregor \& Cunningham, 2008). In this research, we examine the correlations among classical-type problems, and whether different groups of problems differ systematically in difficulty.

\section{Classification of insight problems}

Table 2 shows how we classified the 10 insight problems, where each of the 6 characteristics represents a type of restructuring which has to occur to solve a problem. As is shown, all of these problems were judged to require the spatial re-arrangement of objects (moving coins or sticks), a characteristic which may be typical of certain puzzle-like insight problems. 
All of the problems were judged to involve a misdirect. However, the other characteristics were distributed among the problems in different ways, suggesting that problems may tend to group in a number of possible combinations.

For example, the first three problems in group 1 require that a problem solver disassemble an existing structure before restructuring. The coin triangle starts from a specific organization or configuration which must be disorganized before

TABL $\in$ 2. Assessment of Types of Restructuring Required for Solving Insight Problems.

\begin{tabular}{|c|c|c|c|c|c|c|}
\hline $\begin{array}{l}\text { Problem } \\
\text { definition }\end{array}$ & $\begin{array}{c}\text { Need to } \\
\text { (a) change spatial } \\
\text { assumptions } \\
\text { or (b) compute } \\
\text { alternative } \\
\text { forms in } \\
\text { restructuring } \\
\end{array}$ & $\begin{array}{l}\text { Need to } \\
\text { disassemble } \\
\text { existing } \\
\text { structures or } \\
\text { forms } \\
\text { before } \\
\text { restructuring }\end{array}$ & $\begin{array}{l}\text { Degree } \\
\text { of } \\
\text { Misdirect }\end{array}$ & $\begin{array}{l}\text { Difficulty in (a) } \\
\text { conceptualizing } \\
\text { solution in } \\
\text { starting or } \\
\text { (b) verifying } \\
\text { insightful } \\
\text { solution }\end{array}$ & $\begin{array}{l}\text { More } \\
\text { than one } \\
\text { insight } \\
\text { required } \\
\text { in } \\
\text { problem- } \\
\text { solving }\end{array}$ & $\begin{array}{l}\text { Figure } \\
\text { ground } \\
\text { reversal }\end{array}$ \\
\hline $\begin{array}{l}\text { Move } 3 \\
\text { coins to } \\
\text { reverse } \\
\text { triangle }\end{array}$ & $1(\mathrm{a})$ & 1 & 1 & 0 & 0 & 0 \\
\hline $\begin{array}{l}\text { Move } 3 \\
\text { sticks to } \\
\text { change } \\
\text { pattern }\end{array}$ & $1(\mathrm{a})$ & 1 & 1 & 0 & 0 & 0 \\
\hline $\begin{array}{l}\text { Arrange } 6 \\
\text { coins to } \\
\text { touch }\end{array}$ & $1(\mathrm{a})$ & 1 & 1 & $1(\mathrm{a})$ & 0 & 0 \\
\hline $\begin{array}{l}\text { Divide pigs } \\
\text { in pigpen }\end{array}$ & $1(\mathrm{a})$ & 0 & 1 & $1(\mathrm{a})$ & 0 & 0 \\
\hline $\begin{array}{l}\text { Arrange } 5 \\
\text { pieces in } \\
\text { a cross } \\
\end{array}$ & $1(\mathrm{a})$ & 0 & 1 & $1(\mathrm{a})$ & 1 & 1 \\
\hline $\begin{array}{l}\text { Arrange } \\
12 \text { discs }\end{array}$ & $1(\mathrm{a})$ & 0 & 1 & $1(\mathrm{a})(\mathrm{b})$ & 1 & 0 \\
\hline $\begin{array}{l}\text { Arrange } \\
12 \text { cards } \\
\text { in a grid }\end{array}$ & $1(\mathrm{a})$ & 0 & 1 & $1(\mathrm{a})$ & 0 & 1 \\
\hline $\begin{array}{l}\text { Separate } \\
\text { animals } \\
\text { into } 4 \text { pens }\end{array}$ & $1(a)(b)$ & 0 & 1 & $1(\mathrm{a})$ & 0 & 0 \\
\hline $\begin{array}{l}\text { Divide field } \\
\text { field into } \\
\text { four equal } \\
\text { parts }\end{array}$ & $1(a)(b)$ & 0 & 1 & $1(\mathrm{a})$ & 0 & 0 \\
\hline $\begin{array}{l}\text { Connect the } \\
\text { necklace } \\
\text { strands }\end{array}$ & $1(a)(b)$ & 1 & 1 & 0 & 0 & 0 \\
\hline
\end{tabular}


being reconfigured. The sticks problem is similar, in that the problem involves reversing the orientation of the given shape. The six coin problem does not intrinsically involve a given starting organization but it did so in the form that we used in the study below, because the coins were arranged initially in a specific topological relationship. Two of the first three problems (triangle and sticks) shared a second characteristic, that the precise "shape" of the solution was provided as part of the problem description. As a result, problem solvers can clearly conceptualize what the solution will look like when they commence problem solving.

Although the first four problems have similar characteristics involving the changing spatial assumptions and misdirection, there are slight differences. The 6 coin and the pigpen problem are different from others in the group in that problem solvers are not clear on what the solution might look like when they begin problem solving. In addition, in the pigpen problem, problem solvers do not have disassemble an existing structure before restructuring.

The next 3 problems in group 2 are similar to those in group 1 in that they involve the spatial re-arrangement of objects and misdirection. None of these problems require disassembly of an existing form, nor do problem solvers have a clear model of what the solution will look like. Two of problems in this group are unique in that they require a sequence of insights in solving. The 12 discs problem, for example, requires (a) using the third dimension, by stacking discs, and (b) placing them on intersections rather than edges. Solving the cross problem may also require two restructurings, of (a) placing the dominant piece diagonally rather than horizontally or vertically, and (b) seeing the "notch" as an interior corner rather than as a gap that must be squared off. This latter restructuring is also an example of figure-ground reversal, where the notch transforms from being seen as a hole that must be filled with part of another piece (figure) to a space between two figural components of the cross. The third problem in this group, the 12 cards problem, also requires a figure-ground reversal. In this case, the problem solver has to stop focusing on the cards and begin focusing on the space where the cards are arranged. Or, to put it another way, to switch from thinking that there are "too many cards" to thinking "there is not enough space" to arrange them in.

The final three problems, on first appearance, illustrate many of the same characteristics as in group 1. However, the problems are unique in that, in addition to changing spatial assumptions, problem solvers have to perform some form of computation. In the field problem, the problem solver has to compute how to place 27 animals in 4 pens so that there is an odd number of animals in each pen; in the necklace problem, the problem solver has to calculate how to connect the four pieces of a necklace within the cost constraint of $\$ 15.00$, where it costs $\$ 2$ to open a link and \$3 to close a link. The field problem involves a different sort of calculation of first dividing the field equally where one of the solution paths can be created by first dividing the field into 12 smaller squares where it is easier to see the solution. Weisberg (1996) suggests that the field and the necklace problems are hybrids as they might also be solved without insight. That is, the problem solver might solve these problems without any deep analysis by simply trying various combinations.

The foregoing classification should be regarded as provisional, since it is based on a small sample of problems, and approximate, since it is based on subjective judgment. In addition, we assigned problems a score of either 1 or 0 on each 
dimension, whereas problems might more realistically vary on a scale between 0 and 1. Furthermore, the dimensions we identified are not necessarily equally important, whereas our classification has essentially given them equal weighting. Nevertheless, it provides an initial typology of problems against which to compare the empirical findings below.

\section{REMOTE ASSOCIATES TEST (RAT) ITEMS AND REBUS PUZZLES}

In addition to the 10 spatial problems described above we used a set of Remote Associates Test (RAT) items (Mednick, 1962; Bowden E Jung-Beeman, 2003b). The task in a RAT problem is, given three words, to find a fourth word that connects them. (For example, lick, mine, shaker: Answer, salt.) RAT problems require problem solvers to search for distantly related information, and have become a benchmark test of creativity (Mednick, 1962). RAT items have been used as stimuli in previous studies of insight and related phenomena (Ansburg, 2000; Beeman E Bowden, 2000; Bowden and Jung-Beeman, 2003a; Bowers, Regehr, Balthazard E Parker, 1990; Dallob E Dominowski, 1993; Schooler E Melcher, 1995; Smith \& Blankenship, 1991; Wiley, 1998). Evidence that RAT items are solved by insight has been presented in the form of correlations with performance on insight problems (Ansburg, 2000) and correlations of rated insight with degree of solution priming (Bowden \& Jung-Beeman, 2003a).

In addition to RAT items, we also used rebus puzzles (also known as "wordies"). Rebus problems combine verbal and visual or spatial cues that have to be deciphered into a common phrase or saying (for example you just me= "just between you and me"). Rebus puzzles have been used to study the insight-related phenomena of fixation and incubation (Smith E Blankenship, 1989). Recently, we reported experimental evidence indicating that rebus puzzles operate like insight problems (MacGregor \& Cunningham, 2008).

RAT items and rebus puzzles are alike in that both are verbal. However, they differ in that rebus puzzles also typically involve visual or spatial elements as critical components of the problem. We re-examined our previous classification of 152 rebus puzzles (MacGregor \& Cunningham, 2008) and found that $82 \%$ involved spatial relationships or other visual cues. It has been suggested that there are differences between spatial and verbal insight problems (Dow E Mayer, 2004). We conjecture that rebus puzzles, since they typically involve spatial and verbal elements, should overlap with both spatial and verbal insight problems to a greater extent than spatial and verbal problems do with each other.

Hypothesis 2. Performance scores on rebus puzzles will correlate more highly with performance on classic-type spatial insight problems and with RAT items than spatial problems and RAT items will correlate with each other.

\section{Porticiponts}

\section{METHOD}

The participants were 256 student volunteers at the University of Waikato in New Zealand. Our New Zealand colleagues administered the procedure during November of 2007 to four separate third year classes in the Faculty of Business Administration. The findings reported here are based on a sub-sample of 172 native English speakers, consisting of 84 males and 88 females, ranging in age from under 20 to approximately 30 years. 


\section{DESIGN AND PROCEDURE}

Test materials consisted of the 10 classic-type spatial insight problems described in the previous section and 24 RAT (Remote Associates Test) problems and 24 rebus puzzles. We also included a test of fluid intelligence, the Esoteric Analogies Test (Kleitman, Stankov, \& Marsh, 2003; Stankov, Danthiir, Williams, Pallier, Roberts, E Gordon, 2006). This provided a means of assessing whether performance on the other tasks could be explained in terms of fluid intelligence alone. To control for possible order effects, we used four versions of the battery of tests that varied the order of blocks of items. Generally, each version began with a set of 5 insight problems, followed by the RAT (or rebus) problems, followed by the rebus (or RAT) problems, followed by 5 more insight problems. All four versions ended with the 24 item Esoteric Analogies Test. Participants were allowed 15 minutes for each set of 5 classic-type insight problems ( 3 minutes per problem) and 12 minutes each for the RAT, rebus and Esoteric Analogies tests (30s per item). We selected the RAT items to provide a range of difficulty level based on previous findings (Bowden $\mathcal{E}$ Jung-Beeman, 2003a; Bowden $\mathcal{E}$ Jung-Beeman, $2003 b)$. Similarly, we selected rebus problems to reflect different levels of difficulty based on our previously developed restructuring index (MacGregor and Cunningham, 2008).

\section{RESULTS AND DISCUSSION}

We assigned a score of 1 to correct solutions and 0 to incorrect or no solutions. Table 3 provides the point biserial correlation coefficients among the 10 classictype insight problems. The mean proportion of correct solutions for the different problem types are presented in Table 4 . Table 5 reports correlations between performance on groupings of insight problems and scores on the rebus, RAT, and analogies tests.

The results in Table 3 indicate that problems within each of the three groups are generally inter-correlated, although some of the problems in group 1 and 2 are also correlated with each other. For group 1, the six correlation coefficients ranged from 0.11 to 0.27 , with five of the six significant at $p<.05$. For group 2 , the correlations ranged from 0.21 to 0.27 , and all three were significant. Of the three in group 3, only the correlation of 0.26 , between the necklace and field problems, was significant. These last three problems had the lowest solution rates, and truncated range may have been a factor in the low correlations. Gilhooly and Murphy (2005) used both the necklace and field problems in their cluster analysis of insight and non-insight problems. Their analysis placed the necklace problem in a cluster whose other members were considered to be non-insight problems (syllogisms and the Tower of London problem). The field problem was rarely solved in the 5 minute time period, and was dropped from their analysis (Gilhooly E Murphy, 2005).

The results also indicated considerable overlap between the group 1 and group 2 problems. In this case, the correlations ranged from 0.02 to 0.32 , and 10 of the 12 coefficients were significant. This is perhaps not surprising, as all of these problems involve the need to change spatial assumptions in restructuring. However, we note that, of the seven problems in groups 1 and 2, two (12 discs) correlated with those in group 3, which consisted of problems that also involve computations. 
TABL $\in$ 3. Intercorrelations of performance on 10 classic-type insight problems $(\mathrm{N}=172)$.

\begin{tabular}{|c|c|c|c|c|c|c|c|c|c|c|}
\hline & \multicolumn{4}{|c|}{ Group 1} & \multicolumn{3}{|c|}{ Group 2} & \multicolumn{3}{|c|}{ Group 3} \\
\hline & $\begin{array}{c}\text { Move } \\
3 \\
\text { coins }\end{array}$ & $\begin{array}{c}\text { Move } \\
3 \\
\text { coins }\end{array}$ & $\begin{array}{l}\text { Arrange } \\
6 \text { coins } \\
\text { to touch }\end{array}$ & $\begin{array}{l}\text { Divide } \\
\text { pigs }\end{array}$ & $\begin{array}{l}\text { Arrange } \\
\text { pieces } \\
\text { in cross }\end{array}$ & $\begin{array}{l}\text { Move } \\
12 \\
\text { discs }\end{array}$ & $\begin{array}{l}\text { Arrange } \\
12 \\
\text { cards in } \\
\text { a grid }\end{array}$ & $\begin{array}{c}\text { Divide } \\
\text { field } \\
\text { into } \\
\text { parts }\end{array}$ & $\begin{array}{l}\text { Connect } \\
\text { the } \\
\text { necklace } \\
\text { strands }\end{array}$ & \begin{tabular}{|c} 
Separate \\
animals \\
into 4 \\
pens
\end{tabular} \\
\hline $\begin{array}{l}\text { Move } 3 \\
\text { coins to } \\
\text { reverse } \\
\text { triangle }\end{array}$ & 1 & & & & & & & & & \\
\hline $\begin{array}{l}\text { Move } 3 \\
\text { sticks to } \\
\text { change } \\
\text { pattern }\end{array}$ & .25 & 1 & & & & & & & & \\
\hline $\begin{array}{l}\text { Arrange } \\
6 \text { coins } \\
\text { to touch }\end{array}$ & .16 & .20 & 1 & & & & & & & \\
\hline $\begin{array}{l}\text { Divide } \\
\text { pigs in } \\
\text { pigpen }\end{array}$ & .11 & .24 & .27 & 1 & & & & & & \\
\hline $\begin{array}{l}\text { Arrange } \\
5 \text { pieces } \\
\text { in a cross }\end{array}$ & .29 & .27 & .15 & .16 & 1 & & & & & \\
\hline $\begin{array}{l}\text { Move } 12 \\
\text { discs }\end{array}$ & .20 & .02 & .20 & .32 & .27 & 1 & & & & \\
\hline $\begin{array}{l}\text { Arrange } \\
12 \text { cards } \\
\text { in a grid }\end{array}$ & .18 & .28 & .14 & .26 & .25 & .21 & 1 & & & \\
\hline $\begin{array}{l}\text { Divide } \\
\text { field into } \\
\text { four } \\
\text { equal } \\
\text { parts }\end{array}$ & .06 & .14 & .11 & -.05 & .17 & .02 & -.01 & 1 & & \\
\hline $\begin{array}{l}\text { Connect } \\
\text { the } \\
\text { necklace } \\
\text { strands }\end{array}$ & -.03 & -.05 & -.01 & .14 & .07 & .22 & -.03 & .26 & 1 & \\
\hline $\begin{array}{l}\text { Separate } \\
\text { animals } \\
\text { into } 4 \\
\text { pens }\end{array}$ & .09 & .00 & .03 & -.07 & .07 & -.06 & -.05 & -.04 & -.02 & 1 \\
\hline
\end{tabular}

Correlations of $r=>0.15$ significant at $p=.05$

The goal of this analysis is not to define groupings which are absolute, but to indicate that a problem's characteristics might be a reasonable way to approach the uniqueness of, and commonalities among, insight problems. The correlation results provide only partial support for the first hypothesis, which proposed that 
insight problems may be classified according to common characteristics. Problems in group 1 appear to be interrelated, although there might be an argument to consider two subgroups: (i) the triangle and sticks, and (ii) 6 coin and pigpen. The problems in group 2 also appear to be similar, and their inter-correlations with problems in group 1 might reflect the fact that they all require the need to adjust spatial assumptions in restructuring. The problems in group 3 seem to be different from the other problems and, while the field and necklace problem were correlated, the animals problem was unrelated to others, with correlations ranging from -0.07 to 0.09 . This may be attributed to its exceptionally low solution rate, of $1 \%$.

In providing further support for hypothesis 1 , Table 4 summarizes performance on classic-type insight problems and on the RAT, Rebus, and analogy test items. Overall, participants solved $25 \%$ of the classic-type insight problems ( $s=19 \%)$. It is clear that problem solvers found some problems more difficult to solve than others, and this difficulty might be affected by characteristics of the problems. Specifically, difficulty levels seem to map onto the proposed groupings of problems, with group 1 having the highest solution rates, ranging from $57 \%$ to $33 \%$, followed by group 2 , from $24 \%$ to $17 \%$, then group 3 , from $7 \%$ down to $1 \%$.

Within group 1 , the coin triangle and sticks problems had substantially higher solution rates than the 6 coin and pigpen problems, possibly because the goal states in the latter cases were provided in abstract terms only. Problems in group 2 were somewhat more difficult, possibly reflecting the fact that two of these problems require more than one insight. While the cards problem appears to require only one insight - that the table can have gaps - having this realization does not necessarily lead directly to a solution. We observed a number of attempted solutions with gaps that nevertheless were incomplete or incorrect.

Our second hypothesis proposed that scores on rebus puzzles would correlate more highly with both spatial insight and RAT problems than the latter two would correlate with each other. The relevant findings are reported in the first two rows of Table 5. The correlation between the mean solution rates of rebus and insight

TABLE 4. Performance on Problems (Proportion Correct) $\mathrm{N}=172$.

\begin{tabular}{lcc}
\hline \multirow{2}{*}{ Problem } & \multicolumn{2}{c}{ Proportion correct } \\
\cline { 2 - 3 } & Mean & Standard deviation \\
\hline Move 3 coins to reverse triangle & .57 & .50 \\
Move 3 sticks to change pattern & .49 & .50 \\
Arrange 6 coins to touch & .38 & .49 \\
Divide pigs in pigpen & .33 & .47 \\
Arrange 5 pieces in a cross & .24 & .42 \\
Move 12 discs & .22 & .41 \\
Arrange 12 cards in a grid & .17 & .38 \\
Divide field into four equal parts & .07 & .26 \\
Connect the necklace strands & .05 & .21 \\
Separate animals into 4 pens & .01 & .11 \\
Average for all 10 problems & .25 & .19 \\
Rebus problems & .30 & .15 \\
RAT problems & .21 & .13 \\
Analogies. & .46 & .19 \\
\hline
\end{tabular}


problems was 0.36 and between rebus and mean RAT scores, 0.40 . The correlation between insight scores and RAT scores was 0.20 . While all three coefficients were significant $(p<.01)$, both of the correlations involving rebus scores were significantly greater than the correlation between insight and RAT scores (both $p$ 's $<.05)$. The findings supported the second hypothesis.

In addition, we used a verbal measure of fluid intelligence, the Esoteric Analogies Test, to investigate whether the correlations among the presumed insight problems could be explained simply on the basis of differences in intelligence scores. Previous findings have indicated that RAT performance correlates with verbal intelligence (Harris, 2004; Mednick E Andrews, 1967), and we wished to take any influences of this factor into account. From the third row of Table 5. it can be seen that the Esoteric Analogies scores correlated modestly, but significantly, with all three presumed indicators of insight. Although its correlation with the RAT (0.31) was slightly higher than with the spatial insight and rebus problems (0.25 and 0.27, respectively), the differences were not significant.

TABL $\in$ 5. Correlations between mean solution rates for spatial insight problems, Rebus puzzles, RAT items, Esoteric Analogies, and categories of spatial insight problems.

\begin{tabular}{lcccccc}
\hline & Insight & Rebus & RAT & Analogies & Insight 1 & Insight 2 \\
\hline Rebus & .36 & - & & & & \\
RAT & .20 & .40 & - & & & \\
Analogies & .25 & .27 & .31 & - & & \\
Insight 1 & & .31 & .14 & $\underline{.19}$ & - & - \\
Insight 2 & & .35 & .21 & $\underline{.19}$ & .46 & .13 \\
Insight 3 & & .00 & .09 & $\underline{.15}$ & .11 & .13 \\
\hline$n=172, r=0.15$ & significant at .05 (underlined); $r=0.21$ significant at $\mathrm{p}<.01$ (bold).
\end{tabular}

To test whether rebus scores correlated with spatial insight independently of the measure of fluid intelligence, we used hierarchical regression analysis, with spatial insight scores as dependent variable and analogies, RAT and rebus scores as independent variables, entered in that order. The results indicated that rebus performance continued to significantly predict performance on the spatial insight problems, while controlling for the effects of both fluid intelligence and remote associates performance, $F_{\text {change }}(1,167)=14.98, p<.001$. The results provided further evidence for the second hypothesis.

We conducted a similar test to examine whether rebus performance accounts for verbal insight problem solving, independently of fluid intelligence, by using RAT scores as the dependent variable and analogies and rebus scores as independent variables, entered in that order. The results showed that rebus performance remained a significant predictor of RAT scores while controlling for fluid intelligence, $F_{\text {change }}(1,168)=23.26, p<.001$. The result supports the conclusion that solving rebus and RAT problems involves processing that is not completely captured by a verbal measure of fluid intelligence. As a whole, the pattern of results is consistent with the conclusion that spatial and verbal insight problem solving are not identical, that neither can be accounted for wholly in terms of individual differences in fluid intelligence, and that rebus puzzles appear to involve aspects of both 
The last three rows of Table 5 show the correlations among variables broken down by the three categories of spatial insight problem. The results here are relevant to both hypotheses. The three correlations at the bottom right of the table substantiate the earlier conclusion, that group 1 and group 2 problems share some similarities while differing from the group 3 problems. Earlier, we had considered that the low correlations involving group 3 problems might have been due to the effects of truncated range in the latter problems, because of low solution rates. However, it can be seen that the mean scores for the three problems in group 3 correlated significantly with the test of fluid intelligence. This is open to several possible interpretations. It may be that the problems in group 3 are so difficult beyond the supposed critical insight that their solution requires substantial general intellectual ability that masks any independent contribution of "insight ability". On the other hand, perhaps some of the problems in this group do not involve insight. For example, Gilhooly and Murphy (2005) used the necklace problem in their cluster analysis of insight and non-insight problems, and it was placed in a cluster of "non-insight" problems. In either case, the results lend further support to the first hypothesis, in distinguishing group 3 problems from those of groups 1 and 2 .

The results in the second column of the table indicate that rebus puzzles were related to the first two groups of spatial insight problems but not to the third. Hierarchical regression analysis using group 1 scores as dependent variable and analogies, RAT and rebus performance as independent variables (entered in that order) confirmed that rebus scores predicted insight performance independently of the combined effects of fluid intelligence and remote associates performance, $F_{\text {change }}(1,167)=11.60, p=.001$. A parallel analysis showed this to be true when using group 2 scores as dependent variable, $F_{\text {change }}(1,167)=14.55, p<.001$. In addition, the results indicated that RAT scores were significantly related to group 2 insight scores, while controlling for the effects of fluid intelligence, $F_{\text {change }}(1,168)$ $=4.48, \mathrm{p}<.05$, but not to group 1 insight scores, $F_{\text {change }}(1,168)=1.15$.

In relating the results to the classification scheme proposed in Table 2 , several possibilities arise. There appear to be two factors that may account for the observed relationship between rebus puzzles and the group 1 spatial insight problems. First, rebus puzzles may share the property of requiring a shift in spatial assumptions (for example, a shift in thinking of component $A$ being above component $\boldsymbol{B}$ to component $\boldsymbol{B}$ being below component $\boldsymbol{A}$ ). Second, rebus puzzles may often require breaking an existing form (for example, by not reading from left to right or from top to bottom). Rebus puzzles also share characteristics with group 2 insight problems, including changing spatial assumptions and initial difficulty in conceptualizing the solution. Also, like group 2 problems, rebus puzzles may require more than one insight to solve (MacGregor \& Cunningham, 2008). RAT problems also may share several properties with group 2 problems, which could account for the relationship between them. Like group 2 problems, RAT items typically do not require breaking an existing structure, while they do present initial difficulty in conceptualizing the solution. Also, RAT items may require something that is analogous to more than one insight. For example, with an item such as stick, maker, point (answer: match), the solution creates three compound words that are members of different categories, compared with base, basket, foot (answer: ball), whose solution produces compound words from a single category. However, further research is required to determine whether the character- 
istics proposed here can account for the patterns of relationships observed among the different problem types.

This research suggests that there may be different categories of insight problems depending on the characteristics of the restructurings required to solve them. Insight problems might require: (i) changes in spatial and physical assumptions, (ii) changing defined structures and forms, (iii) misdirection, (iv) abstract and non-visualized goals, (v) number or restructuring sequences, and (vi) figureground type reversals. While previous descriptions of the properties of insight problems have tended to apply to insight problems in general (Bowden $\varepsilon$ Beeman, 1998; Jung-Beeman et al., 2004; Weisberg, 1996), we believe that the six characteristics presented here may provide a start to exploring in what ways problems may involve different types of insight. As such, different problem solving strategies, and different forms of training, may be more appropriate for different types of problems. Future research may determine how different insight characteristics relate to the relative difficulty in solving problems.

\section{$R \in F \in N \in C K L A C E R \in N C E S$}

AKIN, Ö., AKIN, C., \& HEINZ III, J. P. (1996) On the process of creativity in puzzles, inventions, and designs. Carnegie Mellon University: Pittsburgh, unpublished paper.

ANSBURG, P. I. (2000) Individual differences in problem solving via insight. Current Psychology, 19: 143-146.

ANSBURG, P. I., \& DOMINOWSKI, R. L. (2000) Promoting insightful problem solving. Journal of Creative Behaviour, 34: 30-60.

BANNISTER, D., \& MAIR, J. M. M. (1968) The evaluation of personal constructs. New York: Academic Press.

BEEMAN, E. M., \& BOWDEN, E. M. (2000) The right hemisphere maintains solution-related activation for yet-to-be solved insight problems. Memory and Cognition, 28: 1231-1241.

BOWDEN, E. M., \& BEEMAN, M. J. (1998) Getting the right idea: Semantic activation in the right hemisphere may help solve insight problems. Psychological Science, 6: 435-440.

BOWDEN, E. M., E JUNG-BEEMAN, M. (2003a) Aha! Insight experience correlates with solution activation in the right hemisphere. Psychological Bulletin Review, 10: 730-737.

BOWDEN, E. M., \& JUNG-BEEMAN, M. (2003b) Normative data for 144 compound remote associates problems. Behavioral Research Methods, Instruments and Computers, 35: 634-639.

BOWERS, K. S., REGEHR, G., BALTHAZARD, C. G., \& PARKER, K. (1990) Intuition in the context of discovery. Cognitive Psychology, 22: 72-110.

CHRONICLE, E. P., MACGREGOR, J. N., \& ORMEROD, T. C. (2004) What makes an insight problem? The roles of heuristics, goal conception and solution recoding in knowledge-lean problems. Journal of Experimental Psychology: Learning, Memory \& Cognition, 30: 14-27.

CUNNINGHAM, J. B., \& MACGREGOR, J. N. (2008) Training insightful problem solving: Effects of realistic and puzzle-like contexts. Creativity Research Journal, 20, 291-296.

DALLOB, P. I.,E DOMINOWSKI, R. L. (1993) Erroneous solutions to verbal insight problems: Effects of highlighting critical material. Paper presented at the annual meeting of the Western Psychological Association, Phoenix AZ.

DOW, G. T., \& MAYER, R. E. (2004). Teaching students to solve insight problems: Evidence for domain specificity in creativity training. Creativity Research Journal, 16, 389-402.

DUNCKER, K. (1945) On problem-solving. Psychological Monographs, 58(5): whole no. 270.

GILHOOLY, K. J., \& MURPHY, P. (2005) Differentiating insight from non-insight problems. Thinking and Reasoning, 11, 279-302.

HARRIS, J. A. (2004). Measured intelligence, achievement, openness to experience, and creativity. Personality and Individual Difference, 36, 913-929

ISAAK, M. I., \& JUST, M. A. (1996) Constraints on thinking in insight and invention. In R. J. Sternberg \& J. E. Davidson, (Eds.), The nature of insight. Paperback ed. pp. 281-325. Cambridge, MA: MIT Press.

JUNG-BEEMAN, M., BOWDEN, E. M., HABERMAN, J., FRYMIARE, J. L., ARAMBEL-LIU, S., GREENBLATT, R., PAUL J. REBER, P. J., KOUNIOS, J. (2004) Neural activity when people solve verbal problems with insight. Public Library of Science Biology, 4, 0500-0510://www.plosbiology.org

KELLY, G. (1955) The psychology of personal constructs. New York: Norton, Vol. 1.

KEDROV, B. M. (1966-1967) On the question of psychology in scientific creativity. Soviet Psychology, 5: $16-37$

KLEITMAN, S., STANKOV, L., \& MARSH, H. W. (2003) Metacognition: Self-concept, cognitive styles, and cognitive correlates. NZARE AARE, Aukland, New Zealand, November. 
KOKINOV, B., HADJIILIEVA, K. \& YOVEVA, M. (1997) Is a hint always useful in problem solving? The influence of pragmatic distance on context effects. Proceedings of the Nineteenth Annual Conference of the Cognitive Science Society, p. 974. Hillsdale, NJ: Lawrence Erlbaum Associates.

MAYER, R. E. (1996) The search for insight: Grappling with Gestalt Psychology's unanswered question. In R. J. Sternberg \& J. E. Davidson, (Eds.), The nature of insight. Paperback ed., pp. 3-32. Cambridge, MA: MIT Press.

MACGREGOR, J. N., \& CUNNINGHAM, J. B. (2008) Rebus puzzles as insight problems. Behavior Research Methods, 40, 263-268.

MACGREGOR, J. N., ORMEROD, T. C., E CHRONICLE, E. P. (2001) Information-processing and insight: A process model of performance on the nine-dot and related problems. Journal of Experimental Psychology: Learning, Memory E Cognition, 27: 176-201.

MAIER, N. R. F. (1931). Reasoning in humans: II. The solution of a problem and its appearance in consciousness. Journal of Comparative Psychology, 12, 181-194.

MEDNICK, S. A. (1962) The associative basis of the creative process. Psychological Review, 69: 220-232.

MEDNICK, S. A., \& ANDREWS, F. M. (1967). Creative thinking and level of intelligence. Journal of Creative Behavior, $1,428-431$.

METCALFE, J. (1986a) Feeling of knowing in memory and problem solving. Journal of Experimental Psychology: Learning, Memory, and Cognition, 12: 288-294.

METCALFE, J. (1986b) Premonitions of insight predict impending error. Journal of Experimental Psychology: Learning, Memory, and Cognition, 12: 623-634.

METCALFE, J., \& WEIBE, D. (1987) Intuition in insight and noninsight problem solving. Memory, and Cognition, 15: 238-246.

NEWEL, A., \& SIMON, H. (1972) Human problem solving. Englewood Cliffs: N.J.:Prentice-Hall.

OHLSSON, S. (1992) Information-processing explanations of insight and related phenomena. In M. T. Keane and K. J. Gilhooly (Eds.), Advances in the psychology of thinking, (Vol. 1, pp. 1-44). London: Harvester Wheatsheaf.

OHLSSON, S. (1984) Restructuring revisited. II An information processing theory of restructuring and insight. Scandinavian Journal of Psychology, 25: 117-129.

PERKINS, D. N. (1981) The mind's best work. Cambridge, MA: Harvard University Press.

SCHOOLER, J. W., OHLSSON, S., \& BROOKS, K. (1993) Thoughts beyond words: When language overshadows insight. Journal of Experimental Psychology: General, 122, 166-183.

SCHOOLER, J. W., \& MELCHER, J. (1995) The ineffability of insight. In S.M.Smith, T.B.Ward \& R.A. Finke, (Eds.), The creative cognition approach pp.97-134. Cambridge, MA: MIT

SMITH, S. M., \& BLANKENSHIP, S. E. (1989) Incubation effects. Bulletin of the Psychonomic Society, 27: 311-314.

SMITH, S. M., WARD, T. B.,E FINKE, R. A. (1995) Cognitive processes in creative contexts. In S.M.Smith, T. B.Ward E R. A. Finke, (Eds.), The creative cognition approach, pp.1-8. Cambridge, MA: MIT Press.

STANKOV, L., \& DANTHIIR, V., WILLIAMS, L. M., PALLIER, G., ROBERTS, R. D., \& GORDON, E. (2006) Intelligence and the tuning-in of brain networks. Learning and Individual Differences, 16: 217-233.

STERNBERG, R. J., \& DAVIDSON, J. E. (1983) Insight in the gifted. Educational Psychologist, 18: 51-57.

SUZUKI, H., ABE, K., HIRAKI, K., \& MIYAZAKI, M. (2001) Cue-readiness in insight problem-solving. In Proceedings of the Twenty-Third Annual Conference of the Cognitive Science Society, pp. 1012 - 1017. Hillsdale, NJ.: Lawrence Erlbaum Associates

TARDIF, T. Z., \& STERNBERG R. J. (1988) What do we know about creativity? In R. J. Sternberg, (Ed.) The nature of creativity: contemporary psychological perspectives. Cambridge, Cambridge University Press: 429-440.

WALKER, B. M., \& WINTER, D. A. (2007) The elaboration of personal construct psychology. Annual Review of Psychology, 58: 453-477.

WALINGA, J. (2007) The Power of Focus: Unlocking Creative Insight and Overcoming Performance Barriers. University of Victoria: Doctoral dissertation

WEISBERG, R. W. (1986) Creativity, genius, and other myths. New York: Freeman.

WEISBERG, R. W. (1996) Prolegomena to theories of insight problem solving: A taxonomy of problems. In R. J. Sternberg $\mathcal{E}$ J. E. Davidson, (Eds.), The nature of insight. Paperback ed., pp.157-196. Cambridge, MA: MIT Press.

WEISBERG, R. W., \& ALBA, J. W. (1981) An examination of the alleged role of "fixation in the generation of pictures. Journal of Experimental Psychology, General, 110: 169-192.

WEISBERG, R. W., \& ALBA, J. W. (1982) Problem solving is not like perception: More on Gestalt theory. Journal of Experimental Psychology, General, 111: 326-330.

WERTHEIMER, M. (1945) Productive thinking. New York: Harper and Row.

WILEY, J. (1998) Expertise as mental set: the effects of domain knowledge in creative problem solving. Memory $\mathcal{E}$ Cognition, 26: 716-730.

J. Barton Cunningham, University of Victoria, School of Public Administration,Victoria, B.C., Canada, V8W 2Y2, bcunning@uvic.ca

James N. MacGregor, University of Victoria, School of Public Administration,Victoria, B.C., Canada, V8W 2Y2, jmacgreg@uvic.ca

Jenny Gibb, University of Waikato, Waikato Management School, Hamilton, New Zealand, jennyg@mngt.waikato.ac.nz Jarrod Haar, University of Waikato, Waikato Management School, Hamilton, New Zealand, haar@mngt.waikato.ac.nz 